\title{
Usefulness of Hammering Sound Frequency Analysis as an Evaluation Method for the Prevention of Trouble during Hip Replacement
}

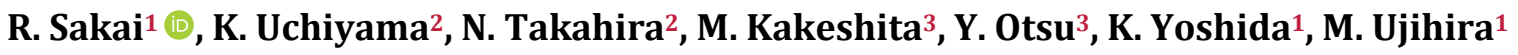 \\ ${ }^{1}$ Department of Biomedical Engineering and Technology, Kitasato University School of Allied Health Sciences, \\ Kanagawa, Japan; ${ }^{2}$ Department of Orthopedic Surgery, Kitasato University School of Medicine, Kanagawa, Japan; \\ ${ }^{3}$ Mark Electronics Co., Ltd., Kanagawa, Japan
}

Correspondence to: R. Sakai, rinax@kitasato-u.ac.jp

Keywords: Hip Replacement, Total Hip Arthroplasty, Hammering Sound, Frequency Analysis, Intraoperative Fracture, Loosening

Received: April 10, $2020 \quad$ Accepted: May 22, $2020 \quad$ Published: May 25, 2020

Copyright $\odot 2020$ by author(s) and Scientific Research Publishing Inc.

This work is licensed under the Creative Commons Attribution International License (CC BY 4.0).

http://creativecommons.org/licenses/by/4.0/

(c) (i) Open Access

\section{ABSTRACT}

In total hip arthroplasty, judgment of the appropriateness of stem hammering is dependent on the experience and feelings of the surgeon and no objective evaluation method has been established. In this study, a frequency analysis of the hammering sounds in total hip arthroplasty was performed to investigate objective judgment criteria capable of preventing problems during surgery. Stem hammering was applied following the surgeon's feelings as usual in an operating room. A directional microphone was placed at a distance about $2 \mathrm{~m}$ from the surgical field and the peak frequency reaching the maximum amplitude was determined by Fourier analysis. It was clarified that the same peak frequency repeats when appropriate fixation is acquired during surgery, suggesting that intraoperative fracture and postoperative loosening can be prevented by stopping hammering at the time the peak frequency converged. Investigation of changes in the hammering sound frequency may serve as objective judgment criteria capable of preventing problems during surgery.

\section{INTRODUCTION}

In cementless fixation of total hip arthroplasty, when hammering counts are not sufficient, fixation failure, such as loosening, is of concern $[1,2]$. When the hammering frequency is increased to prevent fixation failure, the risk of intraoperative fracture increases [3]. Many cases of intraoperative fracture caused by excess hammering have been reported and the incidence is $28 \%$, being high [4-7]. However, in the current situation, judgment of the appropriateness of hammering is dependent on the experience and feelings 
of the operators and no objective evaluation method has been established [3].

In the engineering field, there are two analysis methods of externally observing the inner structure of objects: the vibration analysis method in which vibration is added to an object and the vibration frequency is analyzed, and the acoustic analysis method in which the frequency of sounds generated by hitting an object is analyzed $[8,9]$. In the vibration analysis method, an accelerometer is set to the object and vibration acceleration is measured and analyzed. Highly accurate analytical results are acquired, because the vibration of the analytical object is directly detected, being advantageous, but setting an accelerometer to the object is necessary, being disadvantageous [10]. In the acoustic analysis, sounds generated by the object are collected using a microphone and analyzed $[11,12]$. Sine sounds propagate through the air and it is not necessary to set a device to the object, being advantageous.

To observe hip stem fixation, the vibration analysis method has been employed in which vibration was added to the stem and the frequency was analyzed [13-17]. Rosenstein et al. reported that stem fixation in the femur could be evaluated by the vibration analysis method [18]. Pastrav et al. performed in vivo vibration analysis and concluded that focusing on changes in the frequency is useful to evaluate stem fixation at the time of insertion [15]. However, in vibration analysis performed by Pastrav et al., an accelerometer is attached to the hammer used in surgery, for which slipping into the patient's body is of concern. In contrast, the frequency can be non-invasively analyzed, being advantageous [18].

In this study, hammering sound analysis was performed using the frequency during total hip arthroplasty. Hypothesizing that specific changes in the frequency occur when fixation between the stem and femur is acquired and stopping hammering at this point prevents intraoperative fracture and loosening, we investigated objective judgment criteria capable of preventing intraoperative fracture and loosening by hammering sound analysis.

\section{MATERIALS AND METHODS}

This study has been approved by the institutional review board (IRB) of the organization to which the author belongs (IRB approval number: B11-93, B16-239). The subjects were 16 patients (16 joints) who underwent total hip arthroplasty at Kitasato university hospital between October 2012 and November 2017 ( 7 males and 9 females, mean age: 71.6 years old). Surgery was performed by surgeons specialized in the hip with 20 years or longer experience. In a sound collection environment in an operating room (Figure 1 ), stem hammering was performed following the feelings of the operators as usual.

The sound collection system was comprised of a directional microphone (F-P 5500, Sony, Japan), dual-channel sensor amplifier (SR-2200, Onosokki, Japan), digital storage scope (DSO-2250 USB, Hantek, China), and laptop computer (Endeavor NJ1000, EPSON, Japan) (Figure 2). The directional microphone was set at a distance about $2 \mathrm{~m}$ from the surgical field and sounds were recorded from the initiation to completion of stem hammering by an operator. The hammering sounds collected by the directional microphone were subjected to Fourier analysis and the peak frequency reaching the maximum amplitude was acquired in each hammering. The specific frequencies of the stem and inserter were removed from the acquired values.

Focusing on time-course changes in the peak frequency at a hammering count, when an equivalent value continued at consecutive hammering counts, it was defined as convergence and others were defined as divergence. To determine the definition of convergence, the deviation of the peak frequency before the hammering count and convergence from the corresponding peak frequency was investigated.

\section{RESULTS}

Non-equivalent peak frequencies repeating an increase and decrease were defined as divergence (Figure 3). An equivalent peak frequency continued in 15 of the 16 joints, showing convergence. In the convergence group, an increase and decrease repeated from immediately after stem insertion in all cases and the peak frequency was finally within a constant deviation of $5.18 \pm 2.37$ times on average, in which the mean peak frequency was $3.39 \pm 1.90 \mathrm{kHz}$. 


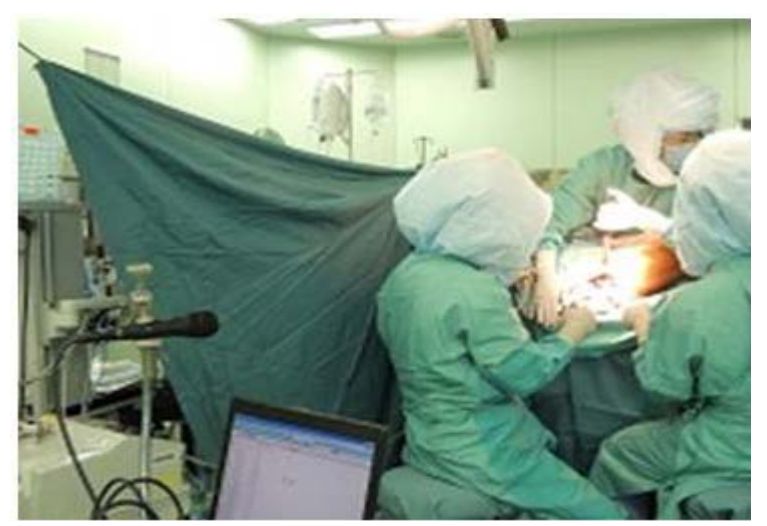

Figure 1. Sound collection environment.

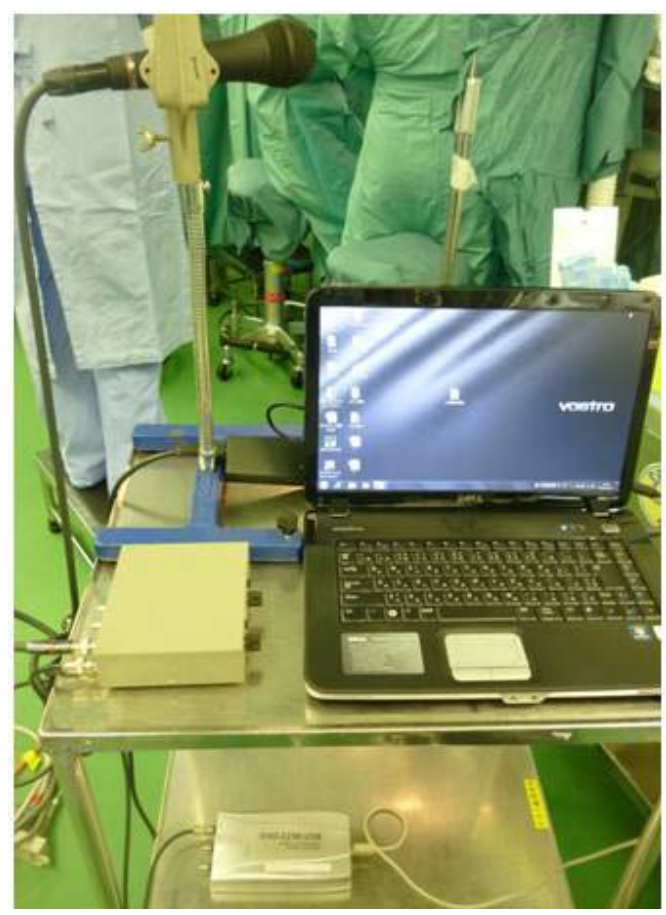

Figure 2. Sound collection device.

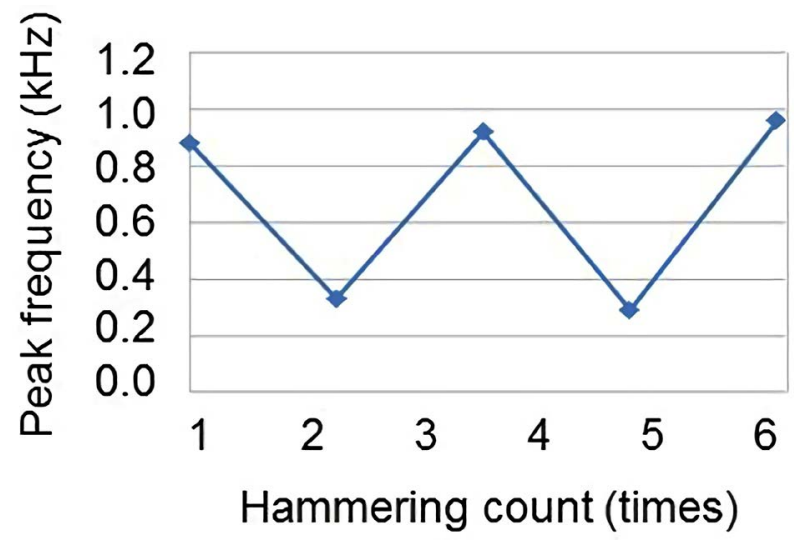

Figure 3. Hammering count and the peak frequency showing divergence. 
The deviation of the converged peak frequency was determined. When the same peak frequency to 3 decimal places was repeated in 7 joints, the deviation was regarded as 0 (Table 1). In one of the examples shown in Figure 4, convergence was noted at the 12th to 14th hammering count, and the deviation of the peak frequency among the 3 hammering counts was 0 .

An equivalent peak frequency within a peak frequency range of $\pm 0.05 \mathrm{kHz}$ was noted in 15 joints. When a deviation of a peak frequency of $\pm 0.02 \mathrm{kHz}$ was defined as constant, the convergence and non-convergence groups included 13 and 2 joints, respectively. When a deviation of a peak frequency of $\pm 0.01 \mathrm{kHz}$ was defined as constant, the convergence and non-convergence groups included 11 and 4 joints, respectively. Figure 5 shows convergence from the 6th to 10th hammering and the deviation of the peak frequency of the 5 hammerings was $\pm 0.02 \mathrm{kHz}$.

Table 1. Converged peak frequencies, the deviation and hammering count.

Converged peak frequencies Deviation of the converged peak Hammering count of converged peak $(\mathrm{kHz}) \quad$ frequencies $(\mathrm{kHz}) \quad$ frequencies (times)

\begin{tabular}{llc}
0.10 & \pm 0.02 & 5 \\
0.33 & \pm 0.01 & 6 \\
0.66 & \pm 0.00 & 3 \\
1.00 & \pm 0.00 & 5 \\
1.78 & \pm 0.00 & 10 \\
1.92 & \pm 0.00 & 4 \\
2.10 & \pm 0.00 & 4 \\
2.50 & \pm 0.05 & 9 \\
2.69 & \pm 0.00 & 7 \\
2.80 & \pm 0.01 & 6 \\
4.00 & \pm 0.00 & 5 \\
4.00 & \pm 0.01 & 7 \\
4.44 & \pm 0.01 & 4 \\
6.00 & \pm 0.02 & 4 \\
6.20 & \pm 0.05 & 4 \\
\hline
\end{tabular}

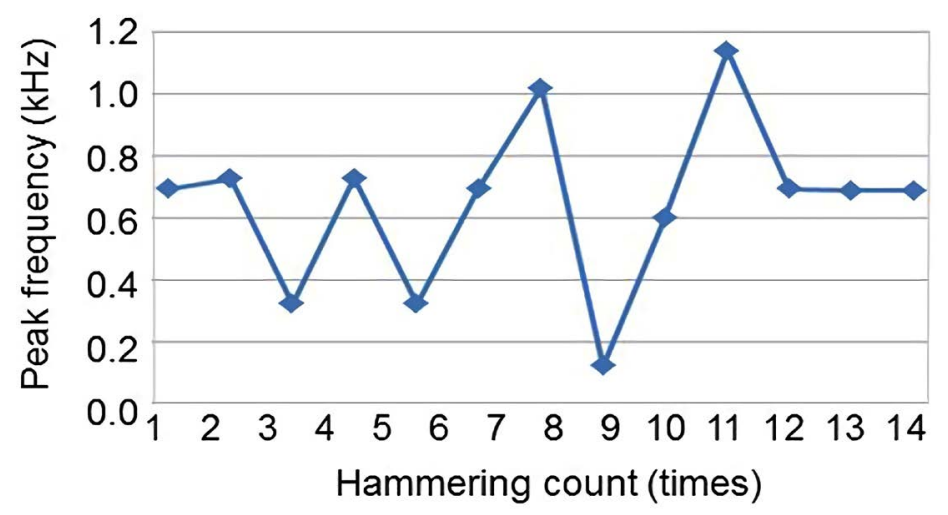

Figure 4. Hammering count and the peak frequency showing convergence. The deviation of the peak frequency among the 3 hammering counts was 0 . 


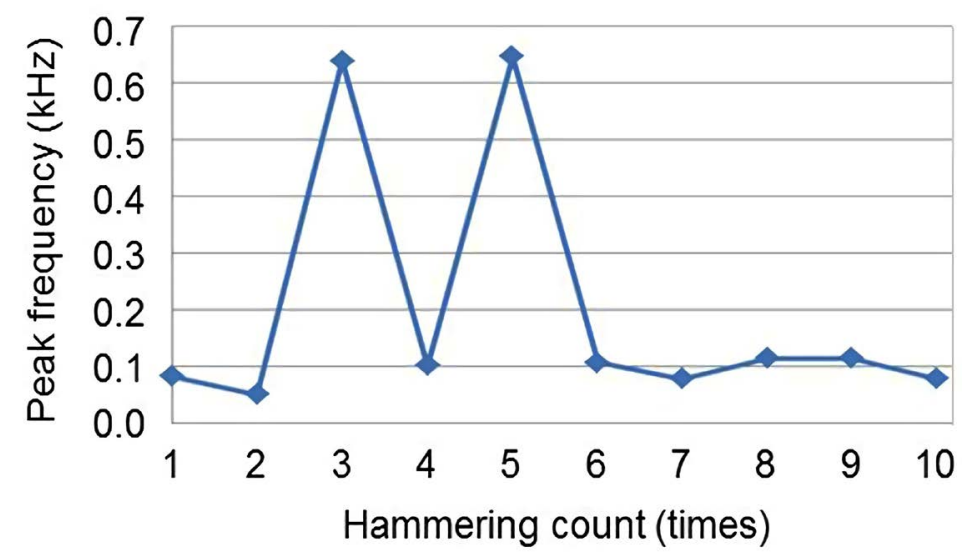

Figure 5. Convergence was shown between 6 and 10 hammering counts. The deviation of the peak frequency during this period was $\pm 0.02 \mathrm{kHz}$.

\section{DISCUSSION}

Jaecques et al. clarified that changes in the peak frequency disappeared as the stem was inserted into the femur in a study using simulated bone [13]. In a clinical study using in vivo bone, the peak frequency became constant at $7 \mathrm{kHz}$ [19]. In our study, a constant peak frequency was noted at a high rate, suggesting that adoption of a specific peak frequency to alert to stop hammering is useful.

It was suggested that this method may be used as a stem fixation evaluation method, as in the vibration analysis method. In addition, real-time sound analysis during surgery is expected to prevent intraoperative fracture, for which a system giving an alert when an equivalent peak frequency continues at specific times. Regarding the definition of constant, since no failure occurred in any case, there may be no problem to a make a judgement setting the deviation at $0.05 \mathrm{kHz}$. Since the safety factor $S$ of the medical devices is 2, a frequency $C$ of 2 - 3 was estimated to be valid to start an alert from a mean count of 5.18 at the constant peak frequency using the formula below [20].

$$
S=5.18 / C=2.59
$$

The increase and decrease in the peak frequency repeated before convergence may have been due to stem movement in the bone in which the stem and femur were unstable and the stem unevenly contacted the femur. In a case showing divergence, there may have been a margin to further continue hammering. However, no sinking or loosening was noted after surgery and fixation was favorable in this case.

Regarding limitations of this study, the deviation was regarded as 0 , but there should be a difference when the order is reduced. However, since the final objective is to prepare a system for surgeons to prevent problems during surgery, we set a difference able to be confirmed at the order of $\mathrm{kHz}$ as a criterion. To clarify the converged peak frequency, quantitative measurement is necessary, for which the bone quality of the subjects should be uniformed. It is necessary to use simulated femur bone because there is individual variation in in-vivo bone or a patient's femur with bone quality clarified by DEXA [21].

\section{CONCLUSIONS}

It was clarified that the peak frequency converges when appropriate fixation is acquired during surgery. It was suggested that intraoperative fracture and loosening can be prevented by stopping hammering at the time the peak frequency converges. Changes in the hammering sound frequency may serve as objective judgment criteria to prevent intraoperative problems.

\section{ACKNOWLEDGEMENTS}

This study was supported by the KAKENHI Grant Number JP 26820160 and 18K04179. 


\section{CONFLICTS OF INTEREST}

The authors did not receive and will not receive any benefits or funding from any commercial party related directly or indirectly to the subject of this article.

\section{REFERENCES}

1. Foster, A.P., Thompson, N.W., John, W. and Charlwood, A.P. (2005) Periprosthetic Femoral Fractures-A Comparison between Cemented and Uncemented Hemiarthroplasties. Injury, 36, 424-429.

https://doi.org/10.1016/j.injury.2004.07.023

2. Sakai, R., Takahashi, A., Takahira, N., Uchiyama, K., Yamamoto, T., Uchida, K., Fukusima, K., Moriya, M., Takaso, M., Itoman, M. and Mabuchi, K. (2011) Hammering Force during Cementless Total Hip Arthroplasty and Risk of Microfracture. HIP International, 21, 330-335. https://doi.org/10.5301/hip.2011.8408

3. Sakai, R., Kikuchi, A., Morita, T., Takahira, N., Uchiyama, K., Yamamoto, T., Moriya, M., Uchida, K., Fukusima, K., Tanaka, K., Takaso, M., Itoman, M. and Mabuchi, K. (2011) Hammering Sound Frequency Analysis and Prevention of Intraoperative Periprosthetic Fractures during Total Hip Arthroplasty. HIP International, 21, 718-723. https://doi.org/10.5301/HIP.2011.8823

4. Götze, C., Steens, W., Vieth, V., Poremba, C., Claes, L. and Steinbeck, J. (2002) Primary Stability in Cementless Femoral Stems: Custom-Made versus Conventional Femoral Prosthesis. Clinical Biomechanics, 17, 267-273. https://doi.org/10.1016/S0268-0033(02)00012-8

5. Schwartz, J.T., Mayer, J.G. and Engh, C.A. (1989) Femoral Fracture during Non-Cemented Total Hip Arthroplasty. Journal of Bone and Joint Surgery, 71, 1135-1142. https://doi.org/10.2106/00004623-198971080-00003

6. Lindahl, H. (2007) Epidemiology of Periprosthetic Femur Fracture around a Total Hip Arthroplasty. Injury, 38, 651-654. https://doi.org/10.1016/j.injury.2007.02.048

7. Moroni, A., Faldini, C., Piras, F. and Giannini, S. (2000) Risk Factors for Intraoperative Femoral Fractures during Total Hip Replacement. Annales Chirurgiae et Gynaecologiae, 89, 113-118.

8. Angulo, Á., Tang, J., Khadimallah, A., Soua, S., Mares, C. and Gan, T.H. (2019) Acoustic Emission Monitoring of Fatigue Crack Growth in Mooring Chains. Applied Sciences, 9, 2176-2187. https://doi.org/10.3390/app9112187

9. Ye, J., Iwata, M., Murakawa, M. and Higuchi, T. (2015) Noise Reduction Methods for Hammering Impact Acoustic Inspection: An Experimental Comparison. Structural Health Monitoring, 1, 1-8. https://doi.org/10.12783/SHM2015/151

10. Crisman, A., Yoder, N., McCuskey, M., Meneghini, M. and Cornwell, P. (2007) Femoral Component Insertion Monitoring Using Human Cadaveric Specimens. 25th Conference and Exposition on Structural Dynamics, Orlando, 19-22 February 2007, 1-15.

11. Meredith, N., Books, K., Fribergs, B., Jemt, T. and Sennerby, L. (2002) Resonance Frequency Measurements of Implant Stability in Vivo. A Cross-Sectional and Longitudinal Study of Resonance Frequency Measurements on Implants in the Edentulous and Partially Dentate Maxilla. Clinical Oral Implants Research, 8, 226-233. https://doi.org/10.1034/j.1600-0501.1997.080309.x

12. Mulier, M., Pastrav, C. and Van der Perre, G. (2008) Per-Operative Vibration Analysis: A Valuable Tool for Defining Correct Stem Insertion: Preliminary Report. Ortopedia Traumatologia Rehabilitacja, 10, 576-582. http://www.ortopedia.com.pl/api/files/view/11323.pdf

13. Jaecques, S.V., Pastrav, C., Zahariuc, A. and Van der Perre, G. (2004) Analysis of the Fixation Quality of Cementless Hip Prostheses Using a Vibrational Technique. Proceedings of ISMA, 443-456.

https://www.researchgate.net/publication/239581322 
https://doi.org/10.1115/ESDA2004-58581

14. Lannocca, M., Varini, E., Cappello, A., Cristofolini, L. and Bialoblocka, E. (2007) Intraoperative Evaluation of Cementless Hip Implant Stability: A Prototype Device Based on Vibration Analysis. Medical Engineering \& Physics, 29, 886-894. https://doi.org/10.1016/j.medengphy.2006.09.011

15. Pastrav, L., Jaecques, S., Jonkers, I., Perre, G. and Mulier, M. (2009) In Vivo Evaluation of a Vibration Analysis Technique for the Per-Operative Monitoring of the Fixation of Hip Prostheses. Journal of Orthopaedic Surgery and Research, 4, 10. https://doi.org/10.1186/1749-799X-4-10

16. Rosenstein, A.D., Bulstrode, C.J., Smith, M., Cunningham, J.L. and Turner-Smith, A.R. (1989) The Differentiation of Loose and Secure Femoral Implants in Total Hip Replacement Using a Vibrational Technique: An Anatomical and Pilot Clinical Study. Proceedings of the Institution of Mechanical Engineers, Part H, 203, 77-81. https://doi.org/10.1243/PIME_PROC_1989_203_014_01

17. Rowlands, A., Duck, F.A. and Cunningham, J.L. (2008) Bone Vibration Measurement Using Ultrasound: Application to Detection of Hip Prosthesis Loosening. Medical Engineering \& Physics, 30, 278-284.

https://doi.org/10.1016/j.medengphy.2007.04.017

18. Whitwell, G., Brockett, C.L., Young, S., Stone, M. and Stewart, T.D. (2013) Spectral Analysis of the Sound Produced during Femoral Broaching and Implant Insertion in Uncemented Total Hip Arthroplasty. Proceedings of the Institution of Mechanical Engineers, Part H, 227, 175-180. https://doi.org/10.1177/0954411912462813

19. Oyama, J., Endo, M.M., Furuichi, I. and Murata, M. (2010) Sound Wave Analysis of Cementless Hip Stem Insertion. Orthopaedic Surgery and Traumatology, 53, 1105-1109.

20. https://online.boneandjoint.org.uk/doi/abs/10.1302/1358-992X.95BSUPP_15.ISTA2012-297

21. Digas, G., Kärrholm, J. and Thanner, J. (2006) Different Loss of BMD Using Uncemented Press-Fit and Whole Polyethylene Cups Fixed with Cement: Repeated DXA Studies in 96 Hips Randomized to 3 Types of Fixation. Acta Orthopaedica, 77, 218-226. https://doi.org/10.1080/17453670610045948 